\title{
Lessons from the prison abolitionist movement in Aotearoa/New Zealand
}

\author{
Ti Lamusse
}

While politics always emerges within specific spaces and time, it is often inspired by movements, ideas, and people beyond that context. This tension between the specificity of the context of Aotearoa/New Zealand, as well as inspiration from abroad and from our ancestors, is key to understanding the history and lessons of People Against Prisons Aotearoa (PAPA). PAPA is a movement that grew out of a specific struggle for queer liberation within a settler colonial capitalist context, while taking lessons from our comrades abroad like Black and Pink, Critical Resistance, Sisters Inside, Angela Davis, and Debbie Kilroy. The purpose of this chapter is to, in turn, share the lessons that we have learned from our distinct form of prison abolitionist movement building, in the hope that our comrades can avoid the mistakes we have made and improve on our collective organising practices.

Origin stories of movements matter a great deal when considering what the movement will eventually become. Organisations like Sisters Inside in Australia, which started in a women's prison, have a group of core organisers that share a life experience of incarceration that orients their work directly toward and with incarcerated women. PAPA's quite different origins, however, explain some of the early and ongoing issues with our organising that organisations like Sisters Inside do not necessarily face.

PAPA first emerged in 2015 from a group of young radical queer and transgender activists in Tāmaki Makaurau/Auckland. While many of us had been arrested and had spent time in police cells, none of us had spent any extended period of time in prison. PAPA also emerged in a New Zealand context where there had not previously been any prison abolitionist movement or organisation. While there had certainly been some high-profile abolitionists, such as Moana Jackson and Tracey McIntosh, PAPA was the first and is currently the only prison abolitionist organisation in Aotearoa. We, nonetheless, emerged from a context of 170 years of Māori resistance to prisons, progressive prison reformers, and the Occupy Movement. Each facet of this context shaped how we first organised and how we organise today.

At first, PAPA was named No Pride in Prisons (NPIP), which formed in response to police and corrections involvement in the 2015 Auckland Lesbian, Gay, Bisexual, Transgender, Takatāpui, ${ }^{1}$ Intersex, and Queer (LGBTTIQ) Pride Parade. NPIP's first action was a disruption and blockading of the 2015 Pride Parade to draw attention to the treatment of transgender women in prison. ${ }^{2}$ The first year and a half of NPIP's organising involved substantial, although 
sporadic, militancy, without much strategic thinking or base building. While we were somewhat effective at staging radical actions, these actions were not building a movement toward abolition.

Throughout 2016 and 2017, NPIP held a series of internal hui (in-depth meetings and discussions) about how we were organising and whether we needed to change. These hui led to some major changes in NPIP, including renaming the organisation People Against Prisons Aotearoa. Much of how we had been organising had not been decided explicitly, such as that we were an exclusively queer and transgender movement, but had grown accidentally or organically. Many of these unintentional decisions were limiting our organising and growth.

Alongside numerous other changes, in 2016/2017, we decided to refocus on becoming a broadbased prison abolitionist organisation (rather than just for queer and transgender people), ${ }^{3}$ with clear democratic structures, guidelines for membership, branches, programmes, and long-term strategies. ${ }^{4}$ Today, PAPA is a broad-based prison abolitionist organisation that combines prisoner advocacy, direct action, campaigning, research, and media advocacy to make the case for prison abolition.

\section{Our kaupapa and how we work}

Part of the process of changing the way we organised involved a series of discussions about what exactly we believed and what was driving our action. The purpose of these discussions was to establish our kaupapa, which refers to the grounding principles that underpin everything we do. These hui ended with a fully written kaupapa that is about a page long and outlines our core principles.

Our kaupapa begins with the statement that the purpose of PAPA "is to achieve prison abolition in Aotearoa. Everything we do is grounded in these fundamental principles" of anticapitalism, decolonisation, prison abolition, alternatives to prison, equality, and solidarity (People Against Prisons Aotearoa, 2017, n.p.). It states,

Prisons do not keep communities safe. Instead, they do serious harm to people in prison and make them more likely to harm others once they leave. While we support immediate reforms to police, courts and prisons which will reduce the damage they cause, we do not believe that justice can be achieved without their complete abolition. Prison abolition means a world without prisons and the violence they create.

(People Against Prisons Aotearoa, 2017, n.p.)

Our kaupapa statement sees the task of prison abolition as inseparable from struggles against colonisation, capitalism, and all other forms of injustice, meaning abolition is just one site of engagement in a much broader struggle.

While this may seem like a basic organisational statement, its completion was a major step forward for our organising. Until then, we had been organising together under the assumption that we all somewhat agreed with each other on what we wanted to achieve but had never actually established that. Finding our shared kaupapa gave us the constant reminder of what our final goal is, which, in turn, helps to guide the work we do and do not do. For outsiders, it also creates a clear understanding of the core beliefs of our organisation and is something that prospective members have to agree with in entirety in order to join PAPA.

\section{How we organise}

Although we clarified our kaupapa years after establishing the organisation, and we now organise very differently from how we did originally, our origins still inform how we organise today. Unlike many of our comrades abroad, we are an entirely volunteer-run organisation. Even if we 


\section{Ti Lamusse}

wanted to hire people to run PAPA's core programmes, we simply do not have the resources to do so, surviving on a couple of hundred New Zealand dollars of dues per week and fundraising.

Instead, our wealth comes from the involvement of our membership. PAPA is a membershiprun organisation, where our members throughout the country ultimately decide what things PAPA does and how. Our members are the people doing the work every day, meaning work only gets done when there is a desire from our members to get it done.

PAPA attempts to ensure democracy at every level of decision making. Our branches, currently in Auckland, Wellington, Christchurch, and Dunedin, is where most of our on-theground organising is coordinated. Branches are led by a smaller group who are elected and subsequently delegated to organising smaller tasks. Branches are also important sites of political discussion, where we collectively self-educate about the criminal injustice system and debate strategies and ideas.

However, most of our work falls outside our fortnightly branch meetings. Social media has enabled us to organise effectively as a national organisation, creating national working groups focussing on areas of work such as media, research, campaigns, prisoner advocacy, and political outreach. Because much of this work can be done online and remotely, even our members living in areas without a branch can contribute to our working groups. Each working group is led by an elected coordinator(s) and makes decisions collectively and democratically, based on a mandate provided by the wider organisation. We also have a Māori caucus. The Māori caucus is constitutionally empowered to overturn certain decisions relating to the Māori world and tino rangatiritanga (absolute Māori self-determination).

Finally, we have a National Organising Committee made up of all working group and caucus coordinators, as well as administrative position-holders, who are all elected by the membership. The purpose of this group is to create a space for national strategising as well as to check in regularly on our collective work. The national body is not empowered to make big decisions, as all major decisions must be debated in branches and voted on by the national membership.

Although there are many limitations with this style of organising, we have found it incredibly useful for growing as an organisation from a small number of people in Auckland doing a small amount of work to a national organisation doing a substantial amount of work and including as many people as possible. Before we adopted this strict, democratic structure, we found that two or three people were doing almost all the work and making all the decisions. Our current structure makes this impossible, ensuring collective decision making and a more equitable (although by no means perfect) distribution of labour.

\section{What we do}

Restructuring PAPA also allowed us to simply do more. In particular, we run three key programmes that serve currently and formerly incarcerated people. These projects are our pen pal network, prisoner advocacy, and support group for formerly incarcerated people.

In 2016, following a visit from a comrade who organises with the Prisoner Correspondence Project (in Turtle Island), we were inspired to start a similar project in Aotearoa. As a result, we launched the Prisoner Correspondence Network (PCN) as a queer and transgender prisoner pen pal network. Transgender women and gay men in prison who PAPA (then NPIP) were already working with engaged with this quickly. They did a lot of work spreading the word about PCN in the prisons. From that small group of prisoners, we have now been in contact with 1,000 people in prison, with around 300 people in prison currently active in the network. This makes PCN, by far, the biggest prisoner pen pal network in Aotearoa, reaching around 3\% of all incarcerated people. The massive growth in PCN continues exponentially, with dozens of 
requests for new pen pals every month. Partly in response to this demand, and because partly PAPA as a whole was no longer a queer- and trans-exclusive movement, we decided to open up the network to all people in prison in 2017, regardless of their sexuality and gender identity. People all over the world have signed up to PCN, which now operates entirely electronically for outside pen pals.

As a side project, PCN also holds annual Christmas card writing and making sessions. In the sessions, hundreds of people across Aotearoa write to people on the inside, ensuring that they receive some love and support during that tough time in prison. We have found that, for people on the outside, this can be a powerful moment of reflection and connection with incarcerated people. On the other hand, every year, we receive numerous letters from incarcerated people telling us how much the cards meant at such a difficult time of year.

Before we started our pen pal network, we had been thrust into prisoner advocacy. Although none of the members at that stage had been in prison (we now have currently and formerly incarcerated members), our high public profile following a series of protests meant that existing LGBTIQ organisations started to look to us for support when LGBTIQ prisoners reached out to them. Consequently, we were linked up with some transgender women in men's prisons who wanted our support. From there, we developed an informal advocacy network, which was later formalised. Our volunteer advocates provide support to people in prison who need help with fighting for or against prison transfers, receiving healthcare entitlements, ensuring that human rights standards are met, and ensuring that their voice is heard by an intransigent Department of Corrections. New advocacy cases are established entirely through word-of-mouth, usually when whānau (extended family) reach out to PAPA asking for help for a loved one on the inside.

Those of us advocating for people on the inside are often faced with difficult choices around how much and what particular actions we are willing and able to take for the people we are working with. As volunteers who are mostly not lawyers, we are much more limited in terms of our time and skills than a paid lawyer. While our advocacy programme has achieved important wins for people on the inside, such as getting them into an education programme, ensuring they get their medication or see a specialist, or getting them moved out of solitary confinement, we have sometimes stumbled because we have not recognised our limits.

At our 2019 Annual General Meeting, responding to a review of the programmes that PAPA provides, we recognised some of these limitations and decided to reduce the scope of our advocacy programme to only providing advocacy to people in prison and not on release. We also put in place clearer structures around training, taking on new cases, and ensuring supervision for advocates. As fundamentally empathetic people, it is hard to say "no" when a person asks for your help. However, from our experience doing this badly, we have learned that saying "yes" to something beyond our capacity is often more harmful or damaging than simply saying "no".

The final major programme we run is a support group for formerly incarcerated LGBTIQ people in Auckland. This programme started at the behest of a recently formerly incarcerated member, who desperately wanted a space to talk through his experiences. Despite some false starts and some issues along the way, we now have a regular support group led by a paid counsellor. OUTSupport provides group support for people coming out of prison with things like welfare, housing, job applications, and group therapy. This is a small, but important, programme for formerly incarcerated people in Auckland, regardless of whether they are members of PAPA.

All of this work is community work that we are proud to do, but which is not necessarily abolitionist in and of itself. Indeed, each of these programmes could be run by a de-politicised nongovernmental organisation (NGO). That is not to say that this work is invaluable. It is usually the most valuable and important work we do. However, prison abolition cannot be achieved through individual advocacy or community support. Prison abolition requires a 


\section{Ti Lamusse}

political transformation. This necessary transformation will not happen because of the kindness of those in power. Prison abolition will only occur when we make it happen, because our movement is too strong to be ignored.

For that reason, PAPA also does a substantial amount of political work. This is the vast majority of the work that the public sees and is focussed on building a prison abolitionist movement and promoting the ideas of prison abolition in Aotearoa. The most public facing of this political work is from our elected press spokesperson, currently Emilie Rākete, and the press working group. At a basic level, the press working group is there to ensure that the radical, and usually more factually accurate, perspective is heard on criminal justice issues in the New Zealand media. Because of the ongoing work of the press working group, PAPA is often a go-to voice on prison issues, ensuring that the public does not only hear from the far-right Sensible Sentencing Trust or liberal apologists.

In order to focus our attention on immediate decarceral reforms, PAPA also runs campaigns that have an abolitionist effect on issues that could make a major difference to incarcerated people and are relatively easy to implement. There are multiple purposes to these campaigns. Most importantly, if and when we win reforms, we stand to substantially improve the lives of the people and communities caught in the net of the criminal injustice system. As abolitionist reforms, we campaign for changes that ultimately reduce the size of the criminal justice system and, in doing so, create space for the more radical argument for the complete abolition of imprisonment. Finally, these campaigns also create momentum for PAPA, driving us forward and providing concrete, achievable tasks which, in turn, makes PAPA more attractive to new members and easier to become involved in. When done well, therefore, our campaigns achieve abolitionist reforms that not only further the idea of abolition but also grow the prison abolitionist movement.

We have run both informal and formal campaigns. Informally, we have been fighting for the enfranchisement of all incarcerated people, giving every person in prison the right to vote. At the last election, more than 7,000 people, about $50 \%$ of whom were Māori, were barred from voting. ${ }^{5}$ PAPA has held protests and put substantial media pressure on the government to change the law that prohibits sentenced prisoners from voting. The prisoner voting ban was partially overturned ahead of the 2020 General Election, with prisoners serving fewer than three years being re-enfranchised.

Our first formal campaign was our campaign to abolish solitary confinement. Much of our early work involved publicly advocating for people in solitary confinement, as well as exposing their conditions. Because of this, and the release of two highly critical reports on solitary confinement in 2017, we decided to launch a formal campaign. Given our experience up to that point, we believed that most people would be on board with ending a degrading and often torturous practice. We hoped that, with some organisation and pressure, this could be winnable.

Once we decided to launch the campaign, our research working group wrote a briefing to the membership about the current conditions in solitary and what specifically we needed to campaign on in order to ban the practice. PCN then sent out letters to all our incarcerated pen pals asking whether they wanted to contribute to a book of collected stories about their experiences in solitary. From there, we had a campaign launch, which garnered a fair bit of attention. At the launch, we had the intention of eventually delivering a petition with tens of thousands of signatures to parliament in about a year's time. Following the launch, we adopted usual political campaign tactics, organising protests, street-based petition signings, parties, public forums, and speaking at relevant events about the campaign.

The most innovative campaign tactic was suggested by a formerly incarcerated member, who proposed we build a mock solitary confinement cell and have people in it in public squares in Auckland. This member felt that people would not understand what solitary really meant unless 
they saw it for themselves. The "solitary cell action", as we came to call it, became a provocative talking point, where our members were able to have frank discussions about the need to abolish solitary with the public. This tactic, however, is not without tension and contradiction. Many formerly incarcerated people came up to us during the actions, thanking us for taking a stand, while others found it too confronting. Although I do not have an easy answer to this tension, it is nonetheless important to note.

As noted earlier, before we launched the campaign, we wrote to all the incarcerated people we were in contact with, asking them whether they wanted to contribute to a collection on their experiences in solitary confinement. These powerful stories have been read out at campaign events and are often the most persuasive argument for the abolition of solitary. They were published in a booklet titled Letters from Lockdown (Rākete et al., 2018).

Another crucial part of our campaign was the release of the report Solitary Confinement in New Zealand Prisons (Lamusse, 2018b). This report, published by the radical left-wing think tank ESRA, outlines exactly what solitary confinement looks like in New Zealand prisons, how common it is, its effects, and what is needed to stop it. It was the single most reported part of our campaign and resulted in a bill being drafted to end solitary confinement. At the time of writing, that bill is currently in the parliamentary caucus of a sympathetic political party.

Because some of our members, including myself, are young academics, we are particularly interested in using the privilege of our education to support the work of the prison abolitionist movement. The research working group, for which I was until recently the coordinator, is responsible for ensuring that PAPA's members are well informed about criminal injustice issues. As abolitionists, our ideas will always come under substantially more scrutiny than the ideas of those who uphold the interests of the powerful. For that reason, research is part of our shield against attacks from people who try to deny and belittle prison abolitionism. Although the moral and political imperative is on the side of abolitionists, the evidence is also on our side. Our research working group, therefore, takes this evidence and ensures that we cannot be criticised for being untruthful or unrealistic. Our commitment to rigorous analysis and evidence makes our arguments stronger.

Alongside the solitary confinement report I mentioned earlier, the research working group has produced numerous other pieces of work that have helped to shift the conversation on the criminal injustice system. In early 2017, we released the report Torture in New Zealand Prisons (Lamusse, 2017), which brings together stories from prisoners and official oversight reports to demonstrate some of the extremely degrading and sometimes torturous conditions that New Zealand prisoners experience.

The first major piece of work, however, was completed before the formal establishment of the research working group. Throughout 2016, about 20 of us collectively wrote the Abolitionist Demands (Lamusse et al., 2016), our book outlining 50 demands which would lead to the abolition of prisons in Aotearoa. Some of these demands include disarming the police, ending solitary confinement, a moratorium on prison construction, defunding police and prisons, and the decolonisation of Aotearoa. We intend to write a second edition of the Abolitionist Demands to reflect our victories, changing priorities and to make it a better book. Beyond these publications, the research working group produces regular internal reports on important research or ideas about the criminal injustice system or movement building.

\section{Ambitions versus limitations}

While PAPA has a lot to be proud of, as a relatively young organisation that is still experimenting with what works best, there are numerous limitations to what we can do. The scale of our project, prison abolition, requires serious ambition. Prison abolition is no easy task. It requires 
an entire transformation of our social and economic conditions. However, there is a tension between the ambitiousness of this project and real limitations on our collective capacities. In this section, I outline the key sources of limitation on what we can do as a prison abolitionist organisation, as both a form of critical organisational reflection and as a potential lesson for others seeking to build abolitionist organisations.

As I have noted throughout this chapter, PAPA is run entirely through volunteer labour. We do not have any paid staff, and all labour is done by our members. Other than our members' engagement, money is the biggest limitation on what PAPA can do. Currently, PAPA is funded by membership dues, donations, merchandise sales, and fundraisers. The revenue we receive from these sources is enough to cover core expenses such as running the pen pal network, transport for advocates to visit prisoners, running events, and other administration. In total, we only have about $\$ 20,000$ (NZ dollars) in annual revenue yet achieve comparable amounts of work to organisations with hundreds of thousands of dollars of revenue with multiple paid positions.

Beyond being unable to afford to pay position holders, we also do not have enough revenue to have our own organising space. We usually hold meetings in spaces lent to us for free from other, sympathetic community organisations. We do not, however, have a PAPA office or centralised meeting space. For a small group that organises reactively or in an ad hoc manner, this is not too important. However, for an organisation that wants to be mass-based and does everyday work serving our communities, running national campaigns, and promoting the importance of abolition, a space of our own is increasingly important.

For example, our pen pal network has now grown so large that it requires a minimum of 40 hours per week of volunteer labour. Without a centralised location for people to work, we rely on students or people with access to good scanners to do much of this work. Other PCN administration requires resources that need to be centralised. Our inability to centralise these resources means that our pool of volunteer labour is much smaller than it could be otherwise. For that reason, the long-term sustainability of PAPA will require us getting enough funding to rent an organising space at some stage.

Prison abolitionist organisations abroad sometimes receive government or other community grants for their work and remain committed to their abolitionist cause regardless. While we respect our overseas comrades' decision to do this, and their ability to maintain their fiery radicalism, this kind of funding is not something we have pursued. As an early adopter of neoliberal reforms (see Kelsey, 2015), the New Zealand government has been particularly effective at co-opting progressive movements into the NGO form. On the radical left in Aotearoa, there is considerable resentment toward organisations that seek big funders and, almost overnight, lose their radical edges. Because we do not wish to compromise our politics for the sake of funders, we are not currently prepared to seek funding from the government for our programmes, even if they were willing to fund us. That means, insofar as funding limits our future growth and capacity, we are further limited by our community's engagement and willingness to financially support our cause.

Volunteers can provide radical organisations with vibrancy, energy, and passion, which can enable organisations like PAPA to do far more than they would have the money to do with paid position holders. However, while paid position holders are clearly not necessary in order to run an effective organisation, depending solely on volunteers has some major downsides. Fundamentally, relying on volunteers means we can only do as much work as people are willing and able to put in. Structurally, volunteer-dependent organisations attract people with more "free" time, such as students and people without dependents. For many people working one or more full-time jobs with dependents, the idea of unpaid political work can simply be too much. Even for those who have time, it is common and expected for our interests change over time, meaning 
people's engagement with the organisation, and willingness to do work, is inconsistent. This inconsistency means work is sometimes left incomplete and projects can stall.

Linked to the issue of volunteer labour, the biggest issue facing PAPA going forward is burnout. PAPA wants to be a sustainable organisation that is fighting for abolition over the long run. We cannot do this if our members get so exhausted from our work that they cannot do it anymore. Burnout is a common issue in activist spaces. A mixture of constant urgency, unsustainable workload, unhealthy interpersonal relationships, conflict, and other issues can simply exhaust activists to the point of dropping out of organising or becoming depressed. While burnout is partially addressed by putting in place clear democratic processes for decision making and creating clear structures for an equitable division of labour, these solutions are insufficient. Since PAPA restructured and put in place these kinds of structures, the distribution of labour improved immeasurably. Nonetheless, people have still experienced burnout following these changes.

Burnout is a symptom of our collective failure to support each other. Everyone coming into activist spaces has their own history that makes them more or less susceptible to burnout. It is our collective responsibility to foster an organising culture that enables people to say no to taking on work and to step back when they are reaching their limits. When we fail to do this, not only is the burnt-out person hurt, but the movement as a whole is undermined. We need to involve as many people as we can if we are going to change the world, so we cannot keep burning through our comrades.

This is not to say that membership-led, volunteer-based organising is bad. In our experience, it has been crucial to the growth of the prison abolitionist movement in Aotearoa. Rather, I highlight these issues because they are a limitation on an otherwise rather effective organising model and, subsequently, need to be addressed. This is something PAPA is currently working on, although it is too early to tell whether our efforts have been successful. ${ }^{6}$ It is certainly a problem about which we hope to learn from our comrades in other movements and abroad.

\section{PAPA is not enough}

In the previous section, I highlighted the limitations on our ambition for abolition. In this final section, I hope to demonstrate, on the other hand, why we also need to be even more ambitious.

Returning to PAPA's kaupapa, it is important to reiterate that we agree with Angela Davis' (2003) analysis that prisons are fundamentally intertwined with racism, patriarchy, and capitalism. Our kaupapa identifies prison abolition as a single site of struggle against these massive forces of oppression and exploitation. It similarly concludes that prison abolition itself is unachievable within capitalism. To achieve prison abolition, we need a revolution in social and economic conditions in order to both make prisons redundant and to properly provide a "constellation of alternative strategies and institutions" (Davis, 2003, p. 107) that ensure that all people live a life of dignity and security.

With that in mind, I turn to one of the most important questions I have been asked as a prison abolitionist organiser: what is your theory of change? How do you think change happens? When I was first asked this, it was ground-shaking for me. Despite years of prior organising, it is a basic question that I had simply never been asked. Until that point, I had been stuck in a pattern of organising because that was simply what we had always done. Very rarely did I think about the long-term impact or trajectory of our organising. Being faced with the question of how we make change, in turn, requires reflection on all our organising activities.

When I think about this question in relation to the task at hand, I cannot help but think that PAPA, as a movement, is not nearly enough to achieve the change we need. If the task is prison abolition, but what is really required is a complete overhaul of our society, it seems to me that 
our organising must be broader. When we require a complete change in the way the economy is run and how we relate to one another, a prison abolitionist movement alone will never be able to create that scale of change. That scale of change requires a movement, organisation, or party that can bring together masses of people to establish our own collective power. PAPA is not that.

Instead, PAPA sits in an uneasy space of being an organisation committed to revolution, which cannot be the vehicle for that revolution, while also fighting for reforms which do not uphold the system. Recognising this tension is not to say that PAPA's work is useless or pointless. Rather, it is crucial, but is not nearly enough. PAPA can and must fight for revolutionary reforms that empower incarcerated people, while also acknowledging the limitations of these reforms and of the abolitionist movement within capitalism generally. ${ }^{7}$

I make this argument not as a directive to abandon your abolitionist movement and to join the local socialist party or anarchist collective. Instead, I highlight it because our work as abolitionists needs to be informed by our long-term strategies. We need to resist the temptation to believe that organising around criminal justice issues is enough. It is never enough. It is a symptom of a wider problem that needs to be addressed on a larger scale. So, by all means, build your prison abolitionist movements with everything you have got, but know that it is only part of the work. Change requires more from us.

\section{Notes}

1 According to the leading Māori scholar on takatāpui Elizabeth Kerekere, takatāpui is "a traditional term meaning 'intimate companion of the same sex.' It has been reclaimed to embrace all Māori who identify with diverse genders and sexualities" (2016, p. 2).

2 For a detailed analysis of No Pride in Prisons' disruptions of the 2015 Pride Parade, see Lamusse (2016).

3 We provide detailed reasoning for this refocussing here: No Pride in Prisons (2017).

4 I explore these changes in greater depth in "Strategies for Building the Revolutionary Left" (Lamusse, 2018a). While that article is largely in praise of the changes we made, and the lessons we learned from our mistakes, I hope this chapter offers a reflection on where we still need to go and the limitations of our current organising.

5 Based on my analysis of a response to a freedom of information request about prisoner numbers on the last election day (Waggott, 2017).

6 Some practices we have put in place to avoid burnout include paid supervision members in high-stress/risk work, having regular collective discussion of burnout and setting boundaries, holding joyful nonpolitical events, taking every effort to be more welcoming and inclusive of new members, and having more productive and purposeful branch meetings. These practices, alongside dozens of others, came out of a formal review of PAPA that I prepared for the 2019 PAPA AGM. The review interviewed 12 PAPA members over two months, highlighting key issues with our organising and providing potential ways to move forward.

7 My analysis here is heavily dependent on Luxemburg's (2008) incomparable Reform or Revolution.

\section{References}

Davis, A. Y. (2003) Are Prisons Obsolete?, New York, Seven Stories.

Kelsey, J. (2015) The New Zealand Experiment: A World Model for Structural Adjustment?, Wellington, Bridget Williams Books [Online]. Available at http://natlib-primo.hosted.exlibrisgroup.com/ NLNZ:NLNZ:NLNZ_ALMA11284411190002836 (Accessed 3 June 2019).

Kerekere, E. (2016) Takatāpui: part of the whānau, Auckland, Tiwhanawhana Trust \& Mental Health Foundation of New Zealand.

Lamusse, T. (2016) "Politics at Pride?”, New Zealand Sociology, vol. 31, no. 6, pp. 49-70.

Lamusse, T. (ed.) (2017) Torture in New Zealand Prisons: A Briefing, Auckland, No Pride in Prisons Press.

Lamusse, T. (2018a) "Strategies for Building the Revolutionary Left: A Case Study of Prison Abolitionism in Aotearoa", Counterfutures: Left Thought \& Practice Aotearoa, no. 6, pp. 120-138. 
Lamusse, T. (2018b) Solitary Confinement in New Zealand Prisons, Wellington, Economic and Social Research Aotearoa.

Lamusse, T., Morgan, S. and Rākete, E. (eds.) (2016) Abolitionist Demands: Toward the End of Prisons in Aotearoa, Auckland, No Pride in Prisons Press.

Luxemburg, R. (2008) The Essential Rosa Luxemburg: Reform or Revolution \& The Mass Strike (trans. Integer), Scott, H. (ed), Chicago, IL, Haymarket Books.

No Pride in Prisons (2017) "NPIP: Why We Didn't Protest at the Pride Parade", GayNZ, 27th February [Online]. Available at https://web.archive.org/web/20170423044601/www.gaynz.com/ articles/publish/35/article_19273.php (Accessed 3 June 2019).

People Against Prisons Aotearoa (2017) Our Kaupapa [Online]. Available at https://blog.papa.org.nz/ post/156664206320/our-kaupapa (Accessed 3 June 2019).

Rākete, E., Stone, A., Morgan, S., Lim, J., McIntyre, K., Watson, K. and Zionov, A. (eds.) (2018) Letters from Lockdown: Prisoners Talk About Solitary Confinement in New Zealand, Auckland, People Against Prisons Aotearoa.

Waggott, R. (2017) Sentenced Prisoner Population 23 September 2017 (Official Information Act Response to Ti Lamusse) [Online]. Available at https://fyi.org.nz/request/6634/response/22231/attach/7/C89612\%20 Response.pdf (Accessed 26 October 2017). 